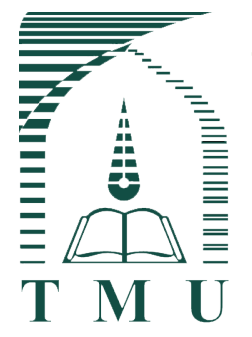

\title{
Incidence of Multidrug-Resistant, Extensively Drug- Resistant, and Pandrug-Resistant Pseudomonas aeruginosa Strains Isolated from Clinical Specimens
}

\section{A R T I C LE I N F O}

Article Type

Original Research

Authors

Fatemeh Poudineh, $M S c^{1}$ Ania Ahani Azari, $P h D^{1^{*}}$ Leila Fozouni, $P h D^{1}$

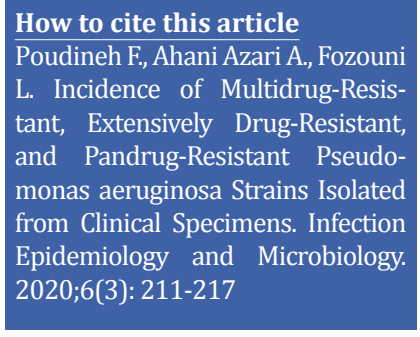

Department of Microbiology, Gorgan Branch, Islamic Azad University, Gorgan, Iran

\section{* Correspondence \\ Address: Department of Microbiology, Gorgan Branch, Islamic Azad University, Gorgan, Iran. \\ ania_783@yahoo.com}

\section{Article History}

Received: June 19,2020

Accepted: July 15,2020

Published: August 15,2020

\section{A B S T R A C T}

Aims: Recently, overuse and misuse of antibiotics have led to the development of multidrugresistant bacteria and infectious diseases caused by these organisms, increasing morbidity and mortality rate in patients. Pseudomonas aeruginosa as a common Gram-negative pathogen is predominantly responsible for hospital-acquired infections. In this study, the prevalence of multidrug-resistant (MDR), extensively drug-resistant (XDR), and pandrug-resistant (PDR) $P$. aeruginosa strains isolated from clinical specimens of patients admitted to a teaching hospital in Gorgan, Iran, was determined.

Materials \& Methods: Clinical samples of blood, urine, burn wound, eye, and secretions (pleural fluid, tracheal or bronchial aspirates and sputum) were collected from all hospitalized patients during a three-month period from April to June 2019. Using conventional biochemical methods, $P$. aeruginosa strains were identified, and the antibiotic resistance pattern was determined by Kirby-Bauer disc diffusion method.

Findings: A total of 40 (25.4\%) P. aeruginosa strains were isolated from 377 clinical specimens. Most of the P. aeruginosa strains were isolated from wound (35\%) and urine (30\%) samples. Most of the $P$. aeruginosa positive samples were recovered from intensive care unit $(32.5 \%)$ and burn ward (30\%). The highest susceptibility was shown to fosfomycin (100\%), and the lowest susceptibility was observed to ceftazidime (87.5\%), followed by aztreonam $(60 \%)$. Based on the results, 52.5 and $20 \%$ of the isolates were MDR and XDR, respectively. All of the MDR isolates exhibited susceptibility to colistin. No PDR phenotype was observed.

Conclusion: Continuous monitoring of drug resistant strains among clinical isolates of $P$. aeruginosa must be done to adopt effective strategies to decrease the threat of antimicrobial resistance.

\section{Keywords: Drug -resistance, Phenotype, Prevalence, Pseudomonas aeruginosa.}

\section{CITATION LINKS}

[1] Pachori P, Gothalwal R, Gandhi P. Emergence of antibiotic resistance... [2] Basak S, Singh P, Rajurkar M. Multidrug-resistant and... [3] Kanani M, Khediri T, Khazaei S, Madani S, Malekianzadeh E. Evaluation of... [4] Mardaneh J, Ahmadi KH, Jahan Sepas A. Determination... [5] Furtado GH, Gales AC, Perdiz LB, Santos AF, Wey SB, Medeiros EA. Risk factors for .. [6] Ha DG, O'Toole GA. c-di-GMP and its effects on biofilm formation and ... [7] Yayan J, Ghebremedhin B, Rasche K. Antibiotic resistance of... [8] Gill JS, Arora S, Khanna SP, Hari Kumar KVS. Prevalence of ... [9] Magiorakos AP, Srinivasan A, Carey RB, Carmeli Y, Falagas ME, Giske CG, et al. Multidrug-resistant, extensively ... [10] Imani Foolad AA, Rostami Z, Shapouri R. Antimicrobial ... [11] Wu AHB. Tietz clinical guide to laboratory tests. 4th ed. Elsevier; 2006, 1620- [12] Clinical and Laboratory Standards Institute. MO2: Performance ... [13] Saderi H, Owlia P. Detection of multidrug resistant (MDR) and ... [14] Shokri D, Rabbani Khorasgani M, Zaghian S, Fatemi SM, Mohkam M, Ghasemi Y, et al. Determination... [15] Bitew A. High prevalence of multi-drug resistance and extended spectrum ... [16] Ghasemian Safaei H, Moghim SH, Nasr Isfahani B, Fazeli H, Poursina F, Yadegari S, et al. Distribution ... [17] Amini A, Ebrahimzadeh Namvar A. Antimicrobial resistance pattern and presence of beta-lactamase ... [18] Moazami-Goudarzi S, Eftekhar F. Assessment of carbapenem susceptibility and ... [19] Ranjbar R, Owlia P, Saderi H, Mansouri S, JonaidiJafari N, Izadi M, et al. Characterization ... [20] Bayani M, Siadati S, Rajabnia R, Taher AA. Drug resistance of Pseudomonas ... [21] Nikokar I, Tishayar A, Flakiyan Z, Alijani K, RehanaBanisaeed S, Hossinpour M, et al. Antibiotic... [22] Salimi H, Yakhchali B, Owlia P, Lari AR. Molecular epidemiology and ... [23] Morales E, Cots F, Sala M, Comas M, Belvis F, Riu M, et al. Hospital costs of nosocomial multi-drug resistant Pseudomonas aeruginosa acquisition. BMC Health Serv... [24] De Francesco MA, Ravizzola G, Peroni L, Bonfanti C, Manca N. Prevalence of multidrug-resistant Acinetobacter baumannii and Pseudomonas aeruginosa in an Italian hospital. J Infect Public... [25] Tacconelli E, Tumbarello M, Bertagnolio S, Citton R, Spanu T, Fadda G, et al. Multidrug-resistant Pseudomonas aeruginosa bloodstream infections: Analysis of trends in prevalence and... 


\section{Introduction}

The incidence of hospital-acquired infections caused by drug-resistant organisms is growing. These infections are difficult to treat and cause the morbidity and mortality rate in patients to be increased ${ }^{[1]}$. In addition, they cause prolonged hospitalization and increase the costs of hospital stay ${ }^{[2]}$. Pseudomonas aeurogenosa as an opportunistic Gramnegative pathogen is responsible for $9-10 \%$ of all nosocomial infections and is the second leading cause of hospitalacquired pneumonia ${ }^{[3-5]}$. It is also one of the main causes of infection in patients with compromised defenses, particularly in intensive care units (ICU) ${ }^{[6]}$. It causes many life-threatening infections in ICU, such as endocarditis, bacteremia, urinary tract infections, cystitis, pneumonia, and surgical wound infections ${ }^{[1,7]}$.

$P$. aeurogenosa is widely distributed in nature and intrinsically resistant to many antibiotics with the capacity to obtain more resistance mechanisms to various classes of antibiotics ${ }^{[1]}$. Therefore, this organism is categorized into various phenotypes based on its drug resistance patterns, including multidrug-resistant (MDR), extensively DR (XDR), and pan-DR (PDR) ${ }^{[8]}$. As described by Magiorakos et al. (2012), MDR is defined as non-susceptibility to one or more antimicrobial agents in three or more antimicrobial categories; XDR is defined as non-susceptibility to one or more antimicrobial agents in all antimicrobial categories, except two or fewer categories; and PDR is defined as non-susceptibility to all antimicrobial agents in all antimicrobial categories ${ }^{[9]}$.

Today, resistance of $P$. aeruginosa strains to multiple antibiotics is a concerning threat due to the limited treatment options. Therefore, antibiotic resistance is a global public health issue and worldwide challenge.
Objectives: The present study aimed to determine the incidence of MDR, XDR, and PDR phenotypes of $P$. aeruginosa in a teaching hospital in Gorgan, Golestan province, Iran.

\section{Materials and Methods}

\section{Sample collection and Identification}

In this cross-sectional study, clinical specimens of blood, urine, burn wound, eye secretion, pleural fluid, and tracheal or bronchial aspirates and sputum were collected from all the patients admitted to an educational hospital in Gorgan, Northeast of Iran, during a three-month period from April to June 2019. These specimens were processed in the laboratory of Islamic Azad University, Gorgan Branch. Information about patients' sex, age, type of specimen, and antibiotic susceptibility was anonymously recorded (Table 1). The collected samples were inoculated on blood agar, MacConkey agar, and EMB agar (Himedia Company, India) plates aseptically, and the plates were incubated at $37^{\circ} \mathrm{C}$ for 24 hrs under aerobic conditions. P. aeruginosa strains were identified based on Gram staining and colonial morphology, oxidase positivity, motility, pigment production, grape-like odor, decarboxylation of arginine, and growth at $42{ }^{\circ} \mathrm{C}{ }^{[10-11]}$.

\section{Antibiotic Susceptibility Assessment}

Antimicrobial susceptibility testing was performed for the isolates using the KirbyBauer disk diffusion method on MuellerHinton agar (Himedia Company, India) medium according to the Clinical and Laboratory Standards Institute (CLSI) guidelines ${ }^{[12]}$. P. aeruginosa ATCC 27853 strain was used for quality control in this study (provided from Tehran University, Faculty of veterinary medicine). The plates were incubated at $37^{\circ} \mathrm{C}$ for $18 \mathrm{hrs}$, and the results were interpreted after measuring 
the zone of inhibition against each of the isolates. The susceptibility of the isolates to each antibiotic was interpreted according to the CLSI guidelines. The isolated bacteria were classified as MDR, XDR, and PDR as described by Magiorakos et al. (2012) [9]. The antimicrobial agents used to classify MDR, XDR, and PDR P.aeruginosa strains are shown in Table 2. All discs were obtained from MAST Company (MAST Chemical Co, UK). Data were analyzed by SPSS software Version 16 using Chi-square test. A $p$-value less than .05 $(p<.05)$ was considered as statistically significant.

\section{Findings}

A total of 157 pathogenic bacteria were isolated from 377 clinical specimens, indicating a culture positivity rate of $41.6 \%$ in clinical specimens. Among which, there were $40 \mathrm{P}$. aeruginosa isolates with a prevalence rate of $25.4 \%$. The rest of the bacterial cultures included Escherichia coli, Klebsiella spp., Acinetobacter spp., Proteus spp., coagulase-negative Staphylococci, and Staphylococcus aureus.

Out of 40 isolates, 16 (40\%) and 34 (85\%) isolates were taken from males and females, respectively. The highest incidence rate of $P$. aeruginosa $(35.5 \%)$ was in the patients over 50 years. Most of the P. aeruginosa strains were isolated from wound (14 out of 40 ) and urine (12 out of 40) samples. Most of the $P$. aeruginosa positive samples were recovered from intensive care unit (ICU) (13 out of 40 ), followed by burn ward (12 out of 40 ). The characteristics of $40 P$. aeruginosa strains isolated are showed in Table 1. There was no significant difference between different age groups and hospital

Table 1) Characteristics of 40 P. aeruginosa strains isolated from patients

\begin{tabular}{|c|c|c|c|c|c|c|c|}
\hline \multirow[b]{2}{*}{ Variables } & \multicolumn{6}{|c|}{ Age Groups } & \multirow[b]{2}{*}{$P$-Value } \\
\hline & $\begin{array}{c}\text { Total } \\
\text { No (\%) }\end{array}$ & $\begin{array}{c}0-10 \\
\text { No (\%) }\end{array}$ & $\begin{array}{c}10-20 \\
\text { No }(\%)\end{array}$ & $\begin{array}{c}20-30 \\
\text { No (\%) }\end{array}$ & $\begin{array}{c}40-50 \\
\text { No }(\%)\end{array}$ & $\begin{array}{c}>50 \\
\text { No }(\%)\end{array}$ & \\
\hline \multirow{5}{*}{ Ward } & $\begin{array}{l}\text { Internal } \\
(8,20 \%)\end{array}$ & $0(0)$ & $0(0)$ & $3(37.5)$ & $0(0)$ & $5(62.5)$ & \multirow{5}{*}{.36} \\
\hline & $\begin{array}{c}\text { ICU } \\
(13,32.5 \%)\end{array}$ & $0(0)$ & $0(0)$ & $7(53.8)$ & $1(7.7)$ & $5(38.5)$ & \\
\hline & $\begin{array}{l}\text { Neonatal } \\
(4,10 \%)\end{array}$ & $4(100)$ & $0(0)$ & $0(0)$ & $0(0)$ & $0(0)$ & \\
\hline & $\begin{array}{c}\text { Burn } \\
(12,30 \%)\end{array}$ & $0(0)$ & $1(8.4)$ & $4(33.3)$ & $4(33.3)$ & $3(25)$ & \\
\hline & $\begin{array}{c}\text { Surgery } \\
(3,7.5 \%)\end{array}$ & $0(0)$ & $0(0)$ & $0(0)$ & $0(0)$ & $3(100)$ & \\
\hline \multirow{5}{*}{ Specimens } & $\begin{array}{c}\text { Burn wound } \\
(14,35 \%)\end{array}$ & $0(0)$ & $1(7.1)$ & $7(50)$ & $1(7.1)$ & $5(35.8)$ & \multirow{5}{*}{$* .04$} \\
\hline & $\begin{array}{c}\text { Urine } \\
(12,30 \%)\end{array}$ & $0(0)$ & $0(0)$ & $4(33.3)$ & $3(25)$ & $5(41.7)$ & \\
\hline & $\begin{array}{c}\text { Eye } \\
(1,2.5 \%)\end{array}$ & $1(100)$ & $0(0)$ & $0(0)$ & $0(0)$ & $0(0)$ & \\
\hline & $\begin{array}{l}\text { Secretion } \\
(3,7.5 \%)\end{array}$ & $3(100)$ & $0(0)$ & $0(0)$ & $0(0)$ & $0(0)$ & \\
\hline & $\begin{array}{c}\text { Blood } \\
(10,25 \%)\end{array}$ & $1(10)$ & $2(20)$ & $3(30)$ & $2(20)$ & $2(20)$ & \\
\hline
\end{tabular}

*Significant difference between the study groups based on the Chi-Square test 
Table 2) Antimicrobial susceptibility of 40 P. aeruginosa strains isolated from patients

\begin{tabular}{|c|c|c|c|c|}
\hline \multirow{2}{*}{ Antimicrobial Categories } & \multirow{2}{*}{ Antimicrobial Agents } & \multicolumn{3}{|c|}{ Number of Isolates (\%) } \\
\hline & & $\mathbf{R}$ & $\mathbf{I}$ & $\mathbf{S}$ \\
\hline \multirow[t]{2}{*}{ Aminoglycosides } & Amikacin $(30 \mu \mathrm{g})$ & $13(32.5)$ & $2(5)$ & $25(62.5)$ \\
\hline & Gentamicin $(10 \mu \mathrm{g})$ & $15(37.5)$ & $1(2.5)$ & $24(60)$ \\
\hline \multirow[t]{2}{*}{ Carbapenems } & Imipenem $(10 \mu \mathrm{g})$ & $11(27.5)$ & $2(5)$ & $27(67.5)$ \\
\hline & Meropenem $(10 \mu \mathrm{g})$ & $15(37.5)$ & $0(0)$ & $25(62.5)$ \\
\hline \multirow[t]{2}{*}{ Cephalosporins } & Ceftazidime $(30 \mu \mathrm{g})$ & $35(87.5)$ & $2(5)$ & $3(7.5)$ \\
\hline & Cefepime $(30 \mu \mathrm{g})$ & $13(32.5)$ & $1(2.5)$ & $26(65)$ \\
\hline \multirow[t]{2}{*}{ Fluoroquinolones } & Ciprofloxacin $(5 \mu \mathrm{g})$ & $20(50)$ & $4(10)$ & $16(40)$ \\
\hline & Levofloxacin (5 $\mu \mathrm{g})$ & $20(50)$ & $3(7.5)$ & $17(42.5)$ \\
\hline \multirow[t]{2}{*}{ Penicillin+ $\beta$-Lactamase inhibitors } & Ticarcillin-clavulanic $(85 \mu \mathrm{g})$ acid & $17(42.5)$ & $10(25)$ & $13(32.5)$ \\
\hline & Piperacillin-tazobactam (110 $\mu \mathrm{g})$ & $19(47.5)$ & $4(10)$ & $17(42.5)$ \\
\hline Monobactams & Aztreonam $(30 \mu \mathrm{g})$ & $24(60)$ & $5(12.5)$ & $11(27.5)$ \\
\hline Phosphonic acids & Fosfomycin $(200 \mu \mathrm{g})$ & $0(0)$ & $0(0)$ & $40(100)$ \\
\hline Polymyxins & Colistin $(10 \mu \mathrm{g})$ & $3(7.5)$ & $0(0)$ & $37(92.5)$ \\
\hline
\end{tabular}

wards under study in terms of the isolation rate $(p=.36)$.

Antimicrobial susceptibility pattern of $40 P$. aeruginosa isolates against 13 antimicrobial agents included in 8 antimicrobial categories is shown in Table 2. The highest susceptibility was shown to phosphonic acids category $(100 \%)$, and the lowest susceptibility was shown to ceftazidime (87.5\%), followed by aztreonam (60\%).

The obtained data showed that 52.5 and $20 \%$ of the isolates were MDR and XDR, respectively. All the MDR isolates exhibited susceptibility to colistin. No PDR phenotype was observed as all the isolates were sensitive to fosfomycin (100\%).

\section{Discussion}

Antibiotic resistance has become as one of the greatest challenges in treating many infectious diseases as well as hospitalacquired infections. These infections are associated with increased morbidity and mortality rate in patients due to the limited treatment options. In recent years, the emergence of drug-resistant $P$. aeruginosa strains, as a common pathogen responsible for hospital-acquired infections, has become a serious threat. This study aimed to determine the prevalence of MDR, XDR, and PDR phenotypes of P. aeruginosa in a teaching hospital in Gorgan, Golestan province, Iran. In this study, the isolates susceptibility rates to amikacin (62.5\%), ticarcillin-clavulanic acid (32.5\%), and colistin (92.5\%) were consistent with those reported in a similar study in Tehran ${ }^{[13]}$. In agreement with a study from India, all the isolates were susceptible to 
fosfomycin (100\%), but to other antibiotics, dissimilar susceptibility rates were observed [8]. In a study by Shokri et al. (2016), the highest and lowest susceptibility rate was observed to ticarcillin-clavulanic acid (90\%) and colistin $(100 \%)$, respectively ${ }^{[14]}$. In a study conducted in Ethiopia, resistance to ceftazidime was reported as $91.8 \%$, which is in line with the result of the present study ${ }^{[15]}$. Ghasemian Safaei et al. (2017) reported the highest antibiotic susceptibility to colistin (91.7\%), which is similar to the findings of the present study and the study by Amini et al. (2019) [16-17].

In the current study, 52.5 and $20 \%$ of the isolates were recognized as MDR and $\mathrm{XDR}$, respectively, which is similar to the findings of another study by Saderi and Owlia in Tehran ${ }^{[13]}$. In a study by Basak et al. (2016), the incidence of MDR (37.1\%) and XDR (13.8\%) isolates was lower than in the present study ${ }^{[2]}$. A high prevalence of MDR (95.8\%) and XDR (87.5\%) isolates was reported by Ghasemian Safaei et al. (2017) in Isfahan ${ }^{[16]}$. In a study from India, $50 \%$ of the isolates were MDR, and $2.3 \%$ were XDR ${ }^{[8]}$. In the studies of Moazami-Goudarzi et al. (2013) and Ranjbar et al. (2011), all of the isolates were characterized as MDR [18-19]. In other Iranian studies, the incidence of MDR strains has been reported as 60, 45.3, and $33.1 \%$, respectively ${ }^{[20-22]}$. However, in foreign studies, lower prevalence rate has been reported ${ }^{[23-25]}$. None of the isolates showed PDR phenotype in the present and aforementioned studies; however, in the study of Shokri et al. (2016), 1.1\% of the isolates were PDR, and a high frequency of MDR (97.9\%) and XDR (65.6\%) phenotypes was observed [14]. In Ethiopia, among $P$. aeruginosa isolates, $6 \%$ were PDR, of which 91.8 and $9.8 \%$ were MDR and XDR, respectively ${ }^{[15]}$.

Considering the results of all the mentioned studies, including the present study, the susceptibility rate of $P$. aeruginosa isolates to antimicrobial agents and the incidence of drug-resistant isolates vary in different geographical regions. The prevalence rate of MDR, XDR, and PDR strains could be varied from 0 to $100,2.3$ to 87.5 , and 0 to $6 \%$, respectively [2,13-15, 18-19]. Differences in antibiotic use, geographical distribution of resistant strains, and history of antibiotic use may be the reasons for these differences [2].

Knowledge of drug-resistant organisms and their incidence in different regions is important in order to adopt appropriate strategies for their control. Thus, detection, infection control practices, and continuous monitoring are highly recommended. Finally, antibiogram testing to select the correct therapy for infections, sensible use of antibiotics, and prevention of selfmedication are among the inevitable necessary measures.

The limitation of the present study is that this study was a single-center study performed for only a three-month period in a teaching hospital in Gorgan. To reveal the development trend of infections caused by different phenotypes of drug-resistant bacteria, performing a multicenter study involving all types of medical systems in the region for at least one year is recommended.

\section{Conclusion}

It could be concluded that continuous detection and monitoring of MDR, XDR, and PDR bacterial strains is needed to decrease the threat of antimicrobial resistance as a recent global challenge.

Acknowledgements: This article was extracted from a master's thesis by Fatemeh Poudineh. The Department of Microbiology of the Islamic Azad University, Gorgan Branch is acknowledged for providing facilities to accomplish the present study. 
Ethical Permissions: This study was approved by the Academic Committee of the Islamic Azad University, Gorgan Branch.

Conflicts of Interests: The authors declared no conflict of interests.

Authors' Contribution: Conceptualization: AAA; Data curation and formal analysis: AAA, FP, LF; Investigation: FP; Methodology and project administration: AAA; Supervision: AAA; Validation: AAA; Writing of original draft:AAA; Writing, reviewing, and editing: AAA, LF.

Funding: None declared by authors. Consent to participate: Not applicable.

\section{References}

1. Pachori $\mathrm{P}$, Gothalwal $\mathrm{R}$, Gandhi $\mathrm{P}$. Emergence of antibiotic resistance Pseudomonas aeruginosa in intensive care unit; A critical review. Genes Dis. 2019; 6(2):109-19.

2. Basak S, Singh P, Rajurkar M. Multidrugresistant and extensively drug-resistant bacteria: A study. J Pathog. 2016; 2016:4065603

3. Kanani M, Khediri T, Khazaei S, Madani S, Malekianzadeh E. Study of psuedomomas aeroginosa resistance to Ceftizidim and Imipenem in Kermanshah Imam reza hospital during 2006-2011. J Lorestan Univ Med Sci. 2012; 15 (4):52-60.

4. Mardaneh J, Ahmadi KH, Jahan Sepas A. Determination antimicrobial resistance profile of Pseudomonas aeruginosa strains isolated from hospitalized patients in Taleghani hospital (Ahvaz, Iran) from 2011-2012. J Fasa Univ Med Sci. 2013; 3(3):188-93.

5. Furtado GH, Gales AC, Perdiz LB, Santos AF, Wey SB, Medeiros EA. Risk factors for hospital-acquired pneumonia caused by imipenem-resistant Pseudomonas aeruginosa in an intensive care unit. Anaesth Intens Care. 2010; 38(6):9941001.
6. Ha DG, O'Toole GA. c-di-GMP and its effects on biofilm formation and dispersion: A Pseudomonas aeruginosa review. Microbiol Spectr. 2015; 3(2):MB0003-2014.

7. Yayan J, Ghebremedhin B, Rasche K. Antibiotic resistance of Pseudomonas aeruginosa in pneumonia at a single university hospital center in Germany over a 10-year period. PLoS One. 2015; 10(10):e0139836.

8. Gill JS, Arora S, Khanna SP, Hari Kumar KVS. Prevalence of multidrug-resistant, extensively drug-resistant, and pandrugresistant Pseudomonas aeruginosa from a tertiary level intensive care unit. J Glob Infect Dis. 2016; 8(4):155-9.

9. Magiorakos AP, Srinivasan A, Carey RB, Carmeli Y, Falagas ME, Giske CG, et al. Multidrug-resistant, extensively drug-resistant, and pandrug-resistant bacteria: An international expert proposal for interim standard definitions for acquired resistance. Clin Microbiol Infect. 2012; 18(3):268-81.

10. Imani Foolad AA, Rostami Z, Shapouri R. Antimicrobial resistance and ESBL prevalence in Pseudomonas aeruginosa strains isolated from clinical specimen by phenotypic and genotypic methods. J Ardabil Univ Med Sci. 2010, 10(3):18998.

11. Wu AHB. Tietz clinical guide to laboratory tests. $4^{\text {th }}$ ed. Elsevier; 2006, 1620-2.

12. Clinical and Laboratory Standards Institute. M02: Performance standards for antimicrobial disk susceptibility tests. Wayne, PA: CLSI; 2018.

13. Saderi H, Owlia P. Detection of multidrug resistant (MDR) and extremely drug resistant(XDR) Pseudomonas aeruginosa isolated from patients in Tehran, Iran. Iran J Pathol. 2015; 10(4):265 - 71.

14. Shokri D, Rabbani Khorasgani M, Zaghian S, Fatemi SM, Mohkam M, Ghasemi 
Y, et al. Determination of acquired resistance profiles of Pseudomonas aeruginosa isolates and characterization of an effective bacteriocin-like inhibitory substance (BLIS) against these isolates. Jundishapur J Microbiol. 2016; 9(8):1-8.

15. Bitew A. High prevalence of multi-drug resistance and extended spectrum beta lactamase production in non-fermenting Gram-negative bacilli in Ethiopia. Infect Dis. 2019; 12:1178633719884951.

16. Ghasemian Safaei H, Moghim SH, Nasr Isfahani B, Fazeli H, Poursina F, Yadegari S, et al. Distribution of the strains of multidrugresistant, extensively drug-resistant, and pandrug-resistant Pseudomonas aeruginosa isolates from burn patients. Adv Biomed Res. 2017; 6:74.

17. Amini A, Ebrahimzadeh Namvar A. Antimicrobial resistance pattern and presence of beta-lactamase genes in Pseudomonas aeruginosa strains isolated from hospitalized patients, Babol-Iran. J Med Bacteriol. 2019; 8(1-2):45-50.

18. Moazami-Goudarzi S, Eftekhar F. Assessment of carbapenem susceptibility and multidrug-resistance in Pseudomonas aeruginosa burn isolates in Tehran. Jundishapur J Microbiol .2013; 6(2):162-5.

19. Ranjbar R, Owlia P, Saderi H, Mansouri $S$, Jonaidi-Jafari $N$, Izadi $M$, et al. Characterization of Pseudomonas aeruginosa strains isolated from burned patients hospitalized in a major burn center in Tehran, Iran. Acta Med Iran. 2011; $\quad 49(10): 675-9$.
20. Bayani M, Siadati S, Rajabnia R, Taher AA. Drug resistance of Pseudomonas aeruginosa and Enterobacter cloacae isolated from ICU, Babol, Northern Iran. Int J Mol Cell Med. 2013; 2(4):204-9.

21. Nikokar I, Tishayar A, Flakiyan Z, Alijani K, Rehana-Banisaeed S, Hossinpour M, et al. Antibiotic resistance and frequency of Class 1 integrons among Pseudomonas aeruginosa isolated from burn patients in Guilan, Iran. Iran J Microbiol. 2013; 5(1):36-41.

22. Salimi H, Yakhchali B, Owlia P, Lari AR. Molecular epidemiology and drug susceptibility of Pseudomonas aeruginosa strains isolated from burn patients. Lab Med. 2010; 41(9):540-4.

23. Morales E, Cots F, Sala M, Comas M, Belvis F, Riu M, et al. Hospital costs of nosocomial multi-drug resistant Pseudomonas aeruginosa acquisition. BMC Health Serv Res. 2012; 12(1):122.

24. De Francesco MA, Ravizzola G, Peroni L, Bonfanti C, Manca N. Prevalence of multidrug-resistant Acinetobacter baumannii and Pseudomonas aeruginosa in an Italian hospital. J Infect Public Health. 2013; 6(3):179-85.

25. Tacconelli E, Tumbarello M, Bertagnolio S, Citton R, Spanu T, Fadda G, et al. Multidrug-resistant Pseudomonas aeruginosa bloodstream infections: Analysis of trends in prevalence and epidemiology. Emerg Infect Dis. 2002; 8(2):220-1. 